\title{
EL ENTENDIMIENTO AGENTE EN MAIMÓNIDES
}

\author{
Juan Fernando Ortega Muñoz \\ Universidad de Málaga
}

\section{RESUMEN}

La Guía de perplejos es una de las mayores obras de la filosofía medieval. Está impregnada de cultura arábigo-musulmana y enraizada en la tradición religiosa e intelectual del judaísmo.

Palabras clave: Guía de perplejos, Maimónides, Judaísmo, Filosofía medieval, Entendimiento agente, Gabirol.

\begin{abstract}
The guide for the Perplexed is one of the most interesting books of the Medieval Philosophie. It is saturated of Arabic culture and it takes root in the intelectual and religious tradition of the Judaism.
\end{abstract}

Key words: The guide of Perplexed, Moses Maimonides, Judaism, Medieval Philosophie, Active Intellect, Avicebron.

\section{INTRODUCCIÓN}

El pensamiento de Maimónides es, sin duda, el más representativo dentro de la filosofía judía de todos los tiempos, según el adagio popular entre los judios que afirmaba que «No hubo nadie de Moisés a Moisés comparable a Moisés», referiéndose al Moisés bíblico y a Maimónides que también se llamaba Moisés. Meir Orian escribe: «El pueblo judío reconoció su superioridad frente a los demás pensadores; vió en él la personificación del alma judía; y en su obra, un legado que perdudará a través de los siglos, trascendiendo los límites de tiempo y espacio» ${ }^{1}$.

Para el pueblo judío Maimónides es el símbolo de perfección humana de todo un pueblo. «Nunca dio un solo hombre tanto a su pueblo y a la humanidad toda como Maimónides. Nunca la obra de un hombre fue tan multifacética como lo fue la suya. Los tratados de Maimónides en sus diversos aspectos se analizaron en academias de estudios religiosos, facultades de medicina y escuelas de filosofía. Nadie fue objeto de tanta admiración y respeto por parte de todas las clases sociales del pueblo: filósofos, rabinos, literatos, hombres de ciencia y poetas; creyentes y no creyentes, judíos y extranjeros» ${ }^{2}$.

1. Meir Orian: Maimónides. Vida, pensamiento y obra. Traducción del hebreo por Zeev Zvi Rosenfeld, Barcelona, Ríopiedras Ediciones, 1984, p. 15

2. Ibidem. 
Esta admiración y reconocimiento del pueblo judio por Maimónides ha sido constante en todos los tiempos. Su contemporáneo, el poeta Tehudá Aljarizi, le dedicó los siguientes versos:

«Ángel de Dios eres tú

y a imagen divina fuiste creado (...)

Por ti dijo el Eterno:

Haremos al hombre a nuestra imagen y semejanzas ${ }^{3}$.

Estas expresiones tan apasionadas testimonian la admiración profunda del pueblo judío por este compatriota, filósofo, jurista, literato, teólogo, médico. Sobre su primera tumba fueron grabadas las siguientes palabras: «Aquí yace Maimónides, lo mejor que ha producido el género humano». Cuando los restos fueron trasladados a Israel y enterrados en la ciudad de Tiberíades, se grabaron sobre su tumba las siguientes palabras:

«Hombre y semidiós, y si hombre fuiste, concibió tu madre de los ángeles celestiales» ${ }^{4}$.

Estas expresiones exaltadas se deben no sólo a la grandeza intelectual y moral de Maimónides, sino también al momento histórico en que le tocó vivir, en el que se radicalizan los integrismos y fanatismos religiosos en las tres religiones del Libro. Maimónides se convierte en bandera que aglutina el sentimiento religioso y cultural de su pueblo. A mi modesto entender, como metafísico lo supera el filósofo malagueño Ibn Gabirol, dentro del marco cultural del pueblo judío, y también lo supera como poeta, pero Maimónides tiene un horizonte más amplio y sus conocimientos abarcan más campos y el mundo de sus intereses culturales se extiende a más zonas, como el Derecho y la Medicina.

Salía el pueblo judío de Al-Andalus, en el tiempo de Maimónides, de un período admirable y ejemplar de convivencia, en que la comunidad judía había gozado de años de prosperidad y paz, espíritu de convivencia quebrado por la invasión de los Almohades, pueblo fanático e intransigente, que impuso su credo religioso de forma cruel y despiadada. El mismo Maimónides se vió forzado a convertirse oficialmente al mahometismo y posteriormente a emigrar por diferentes países del llamado «Cinturón de Alá», con lo que su prestigio se extendió de Al-Andalus hasta Oriente. Ese período nos lo describe Meir Orian con las siguientes palabras: «Los judios que vivían en los países árabes e islămicos constituían una unidad independiente. Nos detendremos en especial en el judaísmo español. Su situación económica era mejor que la de los judíos que vivían en paises cristianos. Los dones naturales de la rica España prodigaron también la abundancia para el judaismo en este país. Por otra parte hasta el fin del primer tercio del s. XII, los musulmanes no interfirieron en la vida interna de las comunidades judías y revelaron tolerancia hacia su religión y tradición. La vida en estas comunidades era apacible, y en varias, gracias a sus dotes intelectuales y a su espíritu de trabajo, lograron los judios escalar los más altos peldaños de la vida social en el gobierno, la administración, la ciencia y aún en el ejercito. Muchos ejercían cargos de médicos en las cortes reales y en los palacios de los altos dignatarios» 5 .

La importancia e influencia de este pensamiento es reconocida así mismo por los pensadores cristianos del Medievo, especialmente por Sto. Tomás, que toman de la hermenéutica biblica hecha por Maimónides el modelo e inspiración para construir su propia hermenéutica «Un pensador del siglo XVI decía que no podía alabarse lo bastante esta obra, que tan de prisa al-

3. Tomado del libro antes citado de Meir Orian, p. 16.

4. Ibidem.

5. Meir Orian, 1. c., p. 29. 
canzó una posición de autoridad en la literatura mundial, convirtiendo a Maimónides en el maestro de la escolástica cristiana. Alejandro de Hales, Alberto Magno, Tomás de Aquino, tomaron sus doctrinas y las utilizaron como ladrillos para edificar sus propios sistemas. Y para el maestro Eckhart, Moisés ben Maimón era una autoridad «a la que sólo se antepone como má- . ximo San Agustín» Y el sistema que estructuró Maimónides fue también importante para el pensamiento de Nicolás de Cusa, Leibniz y Spinozas ${ }^{6}$.

Pero esa adecuación a su época es a un tiempo su grandeza y su limitación. El influjo de este pensador extraordinario muere con la muerte misma de la filosofía medieval. El intento romántico del pueblo judío de mantenerlo vivo en nuestra tradición occidental no excede mucho más allá de los límites de la cultura judía. Esto no quita el reconocimiento de su grandeza y la admiración por una vida consagrada al estudio de la Torah, que supo interpretar y comprender como pocos teólogos de todos los tiempos.

Maimónides nació en Córdoba en 1135 en una familia acomodada. Recibió de su padre su primera educación en Matemáticas, Astronomía, Medicina y Filosofía, pero, sobre todo, una erudita y cordial educación dentro del más estricto espíritu judio y conocimiento de la Torá. En 1148 es conquistada Córdoba por los Almohades y se le impone la conversión al mahometismo. Tras recorrer varias ciudades andaluzas, se traslada a Fez en 1160 y posteriormente a Egipto en 1185. Se establece en Alejandría y abre escuela de Filosofía en Fustat, El Cairo, donde escribe en árabe la mayor parte de sus obras. Saladino le nombró médico de su corte. Fue Jefe de la comunidad judía de Egipto. Muere en Alejandría en 1204.

Entre sus muchos conocimientos Maimónides destaca como teólogo. Su idea obsesiva es compaginar la Toráh con la Filosofía y con la Ciencia de su tiempo, para lo que recurre a la hermenéutica, que sabe utilizar con excelente maestría. «¿A qué se parecen - se preguntalas palabras de la Toráh antes que Salomón hubiese aparecido? A un pozo cuyas frescas aguas estaban hondas, de modo que nadie podía beberlas. ¿Y qué hizo entonces un hombre inteligente? Ató unas sogas con otras y unos cordeles con otros y después sacó agua y bebió. Así, de discurso en discurso y de alegoría en alegoría, llegó Salomón a penetrar en el misterio de la Torah» ${ }^{7}$. Así, mediante la unión de los cordeles de la Filosofía y la Ciencia a la Torah, Maimónides da a beber del «agua de la vida» a su pueblo sediento.

Como dice Abraham Joshua Heschel, «Maimónides estudió Filosofía con el máximo celo: las doctrinas de Alejandro de Afrodisia y de Temistio, de Alfarabí y Algazali, de Saadiá y Bahya, de Yeudá Haleví, de Abraham bar Hiyya, de Abraham ibn Ezra. Pero el único maestro que él reconoció fue Aristóteles: «su sabiduría es la más perfecta que puede poseer el ser humano, prescindiendo de aquellos que por iluminación divina han alcanzado el nivel profético, que es el nivel más sublime que existe» ${ }^{8}$.

\section{LA POSICIÓN DEL ENTENDIMIENTO AGENTE EN EL ORGANIGRAMA GENERAL DEL SISTEMA DE MAIMÓNIDES}

«Has de saber - escribe Maimónides- las teorías formuladas por Aristóteles acerca de las causas de los movimientos en las esferas celestes. De donde deduce la existencia de Inteligencias separadas, aunque se trate de hipótesis indemostrables, son, no obstante, entre las opiniones que pueden enunciarse, las menos expuestas a duda» ${ }^{9}$. Esta afirmación de Maimóni-

6. Abraham Joshua Heschel: Maimónides, Barcelona, Muchnik Editores, 1984, p. 264.

7. Maimónides: Guía de descarriados, Traducción de Suárez Lorenzo, Madrid, s.f., p. 26.

8. Abraham Joshua Heschel: 1. c., p. 38.

9. Maimónides: Guia de perplejos. Edición preparada por David Gonzalo Maeso, Madrid, Editora Nacional, 1984 , p. 256. 
des está fundada en la evidencia que testimonia el Estagirita de que lo que se mueve es movido por alguien exterior a lo que se mueve, a no ser que tenga un principio vital. En vista de ello, al constarnos por la observación expontánea el movimiento de los astros o, como dirían los pensadores de la época, que las esferas celestes se mueven, Maimónides concluye como evidente que tienen alma. Él lo expresa así: «La simple reflexión evidencia que la esfera celeste está dotada de alma» ${ }^{10}$. Lo cual, según él mismo nos dice, no debe entenderse al estilo del alma de los seres vivos, sino que con ello sólo se afirma que «posee un principio en virtud del cual se mueve, y es, con toda seguridad, un alma» ${ }^{11}$.

Es curioso que en razón de la diferencia de movimiento, así también es para Maimónides la diferencia de los principios motores ${ }^{12}$. Los objetos pesados caen hacia abajo, el humo asciende hacia arriba, mientras que los cuerpos celestes se mueven en círculo, lo cual supone, según Maimónides, una inteligencia reguladora que acierta a retornar reiteradamente al principio. «La acción giratoria - afirma Maimónides- solamente podría efectuarse en virtud de una representación determinante de que se mueva así. Empero, ésa solamente es factible por el intelecto y, por ende, la esfera está dotada del mismo» ${ }^{13}$.

Para Maimónides el intelecto tiene por objeto la representación, concebir ideas, mientras que el alma es la causa del movimiento, pero para que éste se produzca hace falta el deseo, que está determinado por un objeto que nos atrae desde fuera. Son estos tres principios combinados entre sí los que determinan el movimiento. Maimónides escribe: «No te mueves de modo alguno hasta que no te sobreviene un deseo impulsivo hacia el objeto representado y sólo entonces te movilizas para la consecución de lo planteado. Queda, pues, claro que ni el alma, autora del movimiento, ni el intelecto, que concibe el objeto, son suficientes para originarlo en tanto no se una la apetencia de la entidad representada. Síguese, pues, de ahí que la esfera celeste posee apetitividad de lo representado, es decir, del objeto deseado, que es Dios» ${ }^{14}$. De esta forma Dios es la última causa del movimiento de las esferas, pero no como causa eficiente, sino final, en virtud del principio aceptado por Maimónides de que «el fin es más noble que las cosas ordenadas al mismo» ${ }^{15}$, por ello que sea Dios, como la realidad más excelente, causa final de todo lo creado, como una especie de imantación que arrastra a las inteligencias, que en este caso son causas eficientes, que orientan la realidad hacia Él. «En este sentido se ha dicho que Dios mueve la esfera celeste, a saber, que ésta apetece asimilarse al objeto de su percepción» 16 .

A Maimónides le resulta impensable un movimiento que de forma autónoma se dinamice por una causa final inmanente al objeto que se mueve, el cuál, según piensa, sólo puede moverse a través del conocimiento, que mediatiza y vincula la causa final con la eficiente, de tal forma que primero es el fin y sólo a partir de él se pone en marcha el proceso que partiendo de la causa eficiente produce el movimiento. Es cierto que en ello Maimónides sigue a Aristóteles, el cual también pensó a Dios como última causa dinamizadora del movimiento, pero no como causa eficiente, sino final.

Dios no sufre mutación al determinar el movimiento, porque no actúa moviéndose, sino que desde su perfecta inmutabilidad ejerce una imantación hacia sí de lạ realidad toda. Son las cosas creadas las que se mueven en virtud de la fuerza gravitatoria, que hace girar toda la realidad en torno a ese centro de concentración del ser, que es Dios mismo. Aunque para Mai-

10. Ibidem.

11. Maimónides: 1. c., p. 257.

12. Ibidem.

13. Ibidem.

14. Ibidem.

15. Maimónides, l. c., p. 272.

16. Maimónides: 1. c., pp. 257-258. 
mónides no parece que se entienda Dios como ser substancial_-ipsum esse subsistens, como dirá Sto. Tomás-, pues en cierto pasaje Maimónides nos dice que el ser surge de la mirada de Dios a las inteligencias separadas. Maimónides afirma: «No hay medio de aprehender la verdadera esencia de Dios (...) y la demostración impone como lo único perceptible «que Él existe». La afirmación de «soy quien soy» de la Biblia es entendida por Maimónides con el significado de que Dios es «ente necesario» ${ }^{17}$, el único existente. En otro lugar afirma Maimónides: «Es cosa demostrada que Dios (...) es el ser «necesario» y no hay en El composición (...). Solamente aprehendemos de Él «que es», pero no «lo que es» ${ }^{18}$.

«El Santo (...) - escribe Maimónides - nada hace antes de haber mirado a la familia superior (las inteligencias separadas). La expresión «mirado» es sorprendente, pues la misma emplea Platón al decir que Dios miró al mundo de las inteligencias y de él emanó el ser» ${ }^{19}$. Como se expresará en nuestra época Heidegger, frente a la mirada de la creatura que necesita la existencia previa del objeto mirado, la mirada de Dios crea el objeto al mirarlo.

La pluralidad de movimientos está determinada por la pluralidad intrínseca del ser. El hecho de esa pluralidad alcanza hasta las esferas. Maimónides escribe: «Son muchas las esferas cuyos movimientos difieren entre sí en velocidad o lentitud, así como en la dirección del mismo, aun cuando todas tengan en común el movimiento circular» ${ }^{20}$. Esta pluralidad de movimientos llevó a Aristóteles - según afirma Maimónides- a afirmar que tal variedad no se explica si no es atribuyendo a las esferas inteligencia. «De ahí concluye categoricamente que existen inteligencias separadas numéricamente iguales a las esferas» ${ }^{21}$. Curiosamente en cierto lugar de la Guía Maimónides interpreta la afirmación escrituraria de que Yavé es «el Señor de los señores» en el sentido de que es el Señor «de las esferas y de los astros» ${ }^{22}$. Para Aristóteles el número de las inteligencias separadas era el mismo que el de las esferas. Aquí alude Maimónides a la doctrina pitagórica de las esferas que situa la tierra en el centro, y el mundo de los planetas y de las estrellas, a la manera de la cebolla, en esferas concéntricas.

El pensador judío Ibn Gabirol, que, como sabemos antecede e influye en el pensamiento de Maimónides ${ }^{23}$, en su célebre poema Keter Malkut distribuye también la realidad en un esquema de esferas concéntricas. Gabirol nos da una visión de un mundo ordenado y estratificado de inspiración evidentemente pitagórica: Como sabemos el pitagorismo está presente en la filosofía española desde su mismo alborear en Moderato de Gades. Gabirol nos describe el mundo desde una visión geocéntrica, situando en el centro a la Tierra, constituida por los cuatro elementos de Empédocles. Partimos de los elementos tierra y agua, que se reparten a mitad el globo terráqueo, al que circunda «la esfera del aire» y sobre ella la «esfera del fuego» ${ }^{24}$. Este núcleo terráqueo está circundado por las diez esferas celestes. La primera está contituida por el firmamento, en el que sitúa la Luna, la cual nos ilumina con la luz reflejada del sol ${ }^{25}$. La segunda está presidida por Mercurio, que es «la estrella de la inteligencia y de la sabiduría» ${ }^{26}$. Gabirol defiende la intervención de los cuerpos celestes, que él considera espíritus, sobre la vida de los hombres y de los seres inferiores. Gabirol va alternando el carácter benéfico y adverso de los diferentes planetas que circundan la tierra. La tercera esfera es la de Venus. La

17. Maimónides: 1. c., p. 179.

18. Maimónides: 1. c., p. 163

19. Maimónides: 1. c., p. 262.

20. Mimónides: 1. c., p. 258.

21. Ibidem.

22. Maimónides: 1. c., p. 261.

23. Meir Orian: 1. c., p. 45.

24. Gabirol: Keter Malku, 10, 62; En Nillas Vallicrosa: La poesia sagrada hebraico-española, Madrid, C.S.I.C., 1948, p. 208.

25. Gabirol: 1. c., 12, 75-89; pp. 208-209

26. Gabirol: 1. c., 13, 96; p. 209. 
cuarta, equidistante de los astros interiores y exteriores, está presidida por el sol, el cual «reparte la luz a todas la estrellas del cielo» ${ }^{27}$. Como astro central del universo celeste, el sol manifiesta poderío y se nos muestra a un tiempo benéfico y adverso. También Maimonides sitúa «el sol en medio (de las esferas) con tres planetas encima y tres debajo» ${ }^{28}$ en lo que sigue a Gabirol y ambos a Tolomeo. La quinta esfera está presidida por Marte, al que, en contrapartida con Venus, Gabirol asigna un papel nefasto. En la sexta esfera sitúa a Júpiter. Es «la estrella de la complacencia y de la amistad. Suscita el temor de Dios, la rectitud y la penitencia y toda buena cualidad» ${ }^{29}$. Como contrapunto, Saturno, que preside la séptima esfera, «despierta guerras, saqueos, cautiverios y hambre...» ${ }^{30}$. Por encima de estas siete esferas y a larga distancia, coloca Gabirol la esfera octava, donde sitúa los signos zodiacales y el resto de las estrellas ${ }^{31}$. La novena esfera, que «circunda todas las esferas y sus criaturas, en su interior encerradas, y dirige todas las estrellas y órbitas de los cielos, es la «esfera del Intelecto» ${ }^{32}$. «Todas las criaturas del mundo son en su interior como un grano de mostaza en el ancho del mar» ${ }^{33}$, aunque respecto a la grandeza del Creador es «nada y vaciedad» ${ }^{34}$. La décima esfera es el «palacio íntimo» del Señor, donde «no alcanza el pensamiento» ${ }^{35}$. «Hasta allí llega el intelecto y alli se para» ${ }^{36}$. Es la morada «de las almas y espíritus excelsos» ${ }^{37}$. Por encima de estas diez esferas, trascendiendo todo lo creado se encuentra Yavé, el Señor, «y nadie subirá hasta $\mathrm{Ti}{ }^{38}$.

Este esquema de las esferas que nos describe Ibn Gabirol en el Keter Malkut permanece en la concepción del emisfério que nos describe Maimónides, el cual se expresa así: «Si los filósofos modernos (entre los que incluye sin duda a Gabirol) han afirmado que las Inteligencias separadas son en número de diez, es porque contaron los globos que tienen astros y la esfera circundante, (aun cuando alguno de aquellos contengan numerosas esferas) y el número de globos es nueve: la esfera circundante universal, la de las estrellas fijas y la de los siete planetas. En cuanto a la décima inteligencia, es el Intelecto Activo, cuya existencia está demostrada por el tránsito de la potencia al acto de nuestro intelecto y por las formas sobrevenidas a los seres sujetos a generación y corrupción tras la situación anterior de su materia en nueva potencia, pues todo cuanto pasa de la potencia al acto necesita perentoriamente, fuera de sí, un actuante, que por necesidad ha de ser de la misma especie de lo actuado» ${ }^{39}$. Como vemos, el intelecto individual necesita ser determinado para conocer por el Intelecto Activo.

Pero además, como más adelante veremos, se manifiesta en este texto de Maimónides el prejuicio de la época de que la materia es pasiva y necesita para moverse de una causa exterior que la ponga en movimiento. «Solamente el ser animado es susceptible de moverse; por consiguiente, se impone la existencia de un alma (en la esfera) y así mismo algo que impulse el movimiento» ${ }^{40}$. Pero lo más grave es que concibe el entendimiento pasivo como justamente eso. pasivo, incapaz de actuar sin la acción exterior del Entendimiento Activo, con lo que

27. Gabirol: 1. c., 15, 106; p. 210.

28. Maimónides: 1. c., pp. 266-267.

29. Gabirol: 1. c., 19, 141-144; p. 212.

30. Gabirol: 1. c., 20, 147; p. 212.

31. Gabirol: 1. c., 21, 153; p. 212.

32. Gabirol: I. c., 24, 169; p. 213.

33. Gabirol: I. c., 23, 167; p. 213.

34. Gabirol: 1. c., 23, 168; p. 213.

35. Gabirol: l. c., 24, 169-170; p. 213.

36. Gabirol: 1. c., 26, 193; p. 214.

37. Gabirol: 1. c., 25, 175; p. 214.

38. Gabirol: 1. c., 26, 194; p. 214.

39. Maimónides: 1. c., p. 258.

40. Maimónides: 1. c., p. 269. 
éste se nos muestra como un inmenso útero del que toman su vida y acción todas las inteligencias individuales. Cada una de estas inteligencias pasivas están unidas por una especie de cordón umbilical a la gran matriz del Entendimiento Agente que de continuo las nutre y determina. Con lo cual permanece en Maimónides de alguna extraña manera y posiblemente por influencia de Ibn Gabirol, el pensamiento de Escoto Eriúgena, el cual defendía que no pensamos nosotros, sino que es el Verbo Divino quien piensa en nosotros y se conoce a sí mismo en nuestro conocimiento. «No sois vosotros lo que me entendeis, sino Yo el que me entiendo a Mí mismo en vosotros a través del Espíritu» ${ }^{41}$.

Conforme con el principio maimonídeo que hemos expuesto con anterioridad de que «todo cuanto pasa de potencia a acto necesita perentoriamente, fuera de sí, un actuante, que por necesidad ha de ser de la misma especie que lo actuado» ${ }^{42}$, Maimónides concluye: «De igual manera, sin duda alguna, lo que confiere la forma es una forma separada, y lo que actualiza el entendimiento es un entendimiento, a saber, el Intelecto Activo, de suerte que la relación de éste con respecto a los elementos y sus componentes es análoga a la de la inteligencia separada perteneciente a cualquier esfera en orden a la misma y la relación del intelecto en acto existente en nosotros, emana del Intelecto Activo y mediante el cual aprehendemos a éste, es idéntica a la del intelecto existente en cada esfera emanado de la Inteligencia separada y mediante el cual la esfera capta a la Inteligencia separada, la aprehende, apetece asimilarse a ella y se pone en movimiento» ${ }^{43}$.

Esta intervención del Entendimiento Agente se convierte en mediática entre Dios y la creatura. La intervención de Dios, según Maimónides, siempre se realiza por mediación de causas interpuestas. «Dios —nos dice- (...) no realiza las cosas por contacto; así, cuando quema, es por mediación del fuego, el cual se mueve por obra de la esfera celeste y ésta a su vez por la actuación de la Inteligencia separada. Éstas son los ángeles, que están cerca de Él y por mediación de ellos se mueven las esferas» ${ }^{44}$. Pero, en última instancia, «Él (Dios) fue quien creó la Inteligencia y las esferas y quien las dotó de sus fuerzas directrices» ${ }^{45}$.

Así tenemos, según Maimonides, un complejo mundo, como una inmensa maquinaria, estructurada como un todo y formada a su vez por un sistema de máquinas menores y dependientes, perfectamente armonizadas con el conjunto de la realidad, una perfecta estructura universal, formada por un sitema de imantaciones (causas finales) y motores (causas eficientes), bajo la dependencia suprema de Dios, causa suprema, que se recrea en la contemplación de esta compleja estructura, como el aficionado a los ferrocarriles disfruta construyendo un sistema de trenes de juguete en un paisaje inventado y construido sobre una inmensa maqueta.

Dios es el «Hacedor de la Inteligencia primera»; ésta «moviliza la primera esfera», de la cual emana la segunda inteligencia, la cual moviliza a su vez la segunda esfera, de la que emana la tercera inteligencia separada... y así sucesivamente, hasta llegar a la última Inteligencia separada, causa del Intelecto Activo. Maimónides nos dice: «la esfera más próxima a nosotros es la causa y principio del Intelecto Activo» ${ }^{46}$. Si no entendemos mal, el Entendimiento Agente ocupa en Maimónides, que computa las esferas comenzando por las más periféricas, el último lugar en el orden de las Inteligencias separadas. «La emanación procedente de Dios - -escribe Maimónides- (...) para producir las Inteligencias separadas, se comunica también de éstas para que unas produzcan a las otras, hasta el Intelecto Activo, en el que finaliza la pro-

41. Escoto Eriúgena: Homil. in Joh. Evg., p. 291

42. Maimónides: 1. c., p. 258.

43. Maimónides: 1. c., p. 259.

44. Ibidem.

45. Maimónides: 1. c., p. 264.

46. Maimónides: l. c., p. 259. 
ducción de las mismas» ${ }^{47}$. Sin embargo en Gabirol el Entendimiento Agente es la novena esfera, la esfera del Intelecto, la más próxima a Dios; la novena, porque comienza contando de dentro a fuera ${ }^{48}$. Dios lo abarca todo.

Conviene hacer una observación: el estilo dogmático con que Maimónides nos presenta su doctrina, se enfrenta al modo más modesto de presentar su filosofía Ibn Gabirol. Produce, sin duda, un poco de malestar en el pensador actual la descalificación que hace Maimónides de cuantos pensamos el cosmos en que vivimos como un sistema de cuerpos físicos «semejantes al fuego y a la tierra». Maimónides nos califica de «ignorantes». Con qué alegre autoridad, un hombre que no contaba con instrumentos materiales ni conceptuales para opinar sobre el mundo exterior, se permite descalificar un pensamiento que en ese momento era, al menos, tan válido como el suyo.

Esta seguridad de Maimónides se fundamenta en lo que él cree afirmar el Texto sagrado. Hay, sin duda, un uso abusivo de la Escritura al hacerle afirmar algo que ésta nunca pretendió; pero no es en verdad esta interpretación teológica en lo que realmente funda su doctrina, sino en su asentimiento radical a los conocimientos de la «ciencia». El pensamiento «científico» del momento afirmaba que «las esferas celestes están reconocidas como seres vivos e inteligentes, quiere decir, que perciben» ${ }^{49}$. «No pienses, sin embargo - afirma Maimónides- que las esferas y las Inteligencias deban equipararse con esas otras fuerzas corpóreas, que constituyen una naturaleza, pero no tienen conciencia de su actividad, sino que esas entidades perciben sus actos y usan de libertad para gobernar (...). Todos estos pasajes te demuestran que dichos entes (Inteligencias separadas y esferas) aprehenden sus actos y tienen voluntad y opción en lo referente al gobierno a ellos confiado... ${ }^{50}$.

Pero lo curioso del caso es que Maimónides lo argumenta «por la Escritura» ${ }^{51}$, esto es, pensando que queda demostrado por el testimonio del texto sagrado, lo que se le manifiesta como una argumentación más convincente. Él se apoya en una interpretación y análisis hermenéutico del texto del salmo 19 , en que se nos dice que «los cielos pregonan la goria de Dios». Parecería lógico interpretar, como defiende la tradición platónico-agustiniana, en el sentido que la belleza y la armonía de los cielos manifiestan la grandeza de su autor, pero Maimónides se empeña en usar el sentido literal del texto. «Cuán lejos del concepto de la verdad —nos diceestaría quien pensara que se trata de una expresión metafórica, dado que los verbos higgîd (anunciar) y sippêr (narrar) no pueden referirse juntos en hebreo sino a un ser dotado de inteligencia» 52 .

Maimónides, al final de su argumentación, vuelve a descalificar a quienes piensan en contra: «Esta prueba escrituraria - nos dice- solamente podría recusarla el ignorante renuente» 53. Pero sin solución de continuidad Maimónides añade: «En cuanto a la opinión de los Sabios sobre el particular, no necesita, a mi juicio, explicación ni prueba» ${ }^{54}$. Con este texto Maimónides implícitamente manifiesta que su doctrina sobre el carácter animado de las esferas está fundada en la opinión generalizada de los sabios y científicos de su época, según un principio que consideraban los sabios incuestionable: «lo superior está vivo, y lo inferior muerto» 55 .

En virtud de este principio se recrea en afirmar que «lo dicho también por Aristóteles sobre la percepción y concepción en la esfera celeste concuerda con las palabras de nuestros profe-

47. Maimónides: 1. c., p. 272.

48. Gabirol: 1. c., 23 y 24.

49. Maimónides: 1. c., p. 260.

50. Maimónides: 1. c., p. 265.

51. Maimónides: 1. c., p. 260.

52. Ibidem.

53. Ibidem.

54. Ibidem.

55. Ibidem. 
tas» ${ }^{56}$. Aquí establece un principio general de especial importancia para el tema que nos ocupa: «Has de saber que los filósofos coinciden en el hecho de que el gobierno de este mundo inferior se realiza por la fuerza que sobre él recae de la esfera celeste, como ya dijimos, y que éstas perciben y conocen lo que rigen» ${ }^{57}$, porque - argumenta — «resulta inadmisible suponer que quien rige una cosa desconozca lo regido» ${ }^{58}$. En otro lugar insiste en esta idea central: «Sabido es y difundido en todas las obras filosóficas sobre el gobierno del cosmos que el régimen de este mundo inferior, quiero decir, el de la generación y la corrupción, se basa en las fuerzas procedentes de las esferas» ${ }^{59}$.

Maimónides parte por tanto del convencimiento de que «todas las esferas son cuerpos vivos, dotados de alma e intelecto, que representan y aprehenden la divinidad, así como también los primeros principios; que existen la Inteligencias separadas, absolutamente incorporeas, todas emanadas de Dios (...) e intermediarias entre Él y todos esos cuerpos celestes» ${ }^{60}$.

Como anteriormente hemos visto en Ibn Gabirol, el Entendimiento agente ocupa, según Maimónides, el primer lugar en la economía de las inteligencias separadas si lo miramos desde Dios, y el último lugar respecto al hombre. Maimónides se expresa así: «La emanación procedente de Dios (¡Ensalsado sea!) para producir las Inteligencias separadas, se comunica también de estas para que unas produzcan a las otras, hasta el Intelecto Activo, en el que finaliza la producción de las mismas» ${ }^{61}$.

\section{EL ENTENDIMIENTO AGENTE COMO ÁNGEL DE DIOS}

Hay en la Guía de Maimónides una interesante equiparación de las Inteligencias separadas, de que hemos hablado con anterioridad, con los ángeles. «Él (Aristóteles) llama inteligencias separadas a lo que nosotros llamamos ángeles» ${ }^{62}$. Gabirol ya había dedicado una extensa parte de su poema religioso Keter Malkut a exponer su visión particular de la angeología. «Los ángeles de tu voluntad (de Dios), los ministros de tu faz. Ellos son ilustres de fuerza y los potentes de imperio (...), cumplidores de todo ministerio, a donde quiera que se encamine el Espíritu (...). Entre ellos hay ejércitos que corren y van incansables e infatigables, videntes y no visibles...» ${ }^{63}$.

Entre las Inteligencias separadas Maimónides destaca como la más importante el Entendimiento Agente. Éste es el motor primero del Universo, pues para Maimónides «todas las estructuras proceden de la acción del Intelecto Activo, y ése es el ángel y el príncipe del mundo, de quien tanto hablan los Doctores» ${ }^{64}$.

La angeología de Maimónides es muy extensa. Llega a afirmar que «todas las facultades son ángeles» ${ }^{65}$. Entendemos que se refiere Maimónides a todas las facultades que emanan de Dios, conforme a la etimología de la palabra. «Bien sabes que el significado de mal'âk (angel) es mensajero; por consiguiente todo quien ejecuta una orden es un mal'âk; y así, los movimientos del animal, incluso irracional, se realizan, según la Escritura, cuando se cumplen de conformidad con el propósito de Dios, que en él puso una fuerza ejecutora de tal movimien-

\footnotetext{
56. Ibidem.

57. Maimónides: 1. c., pp. 260-261.

58. Maimónides: 1. c., p. 261.

59. Maimónides: 1. c., p. 267.

60. Maimónides: l. c., p. 259.

61. Maimónides: l. c., p. 272.

62. Ibidem.

63. Gabirol: 1, c., p. 25.

64. Maimónides: 1. c., p. 263.

65. Ibidem.
} 
to. Dícese, p. e., «Mi Dios ha enviado a su angel, que ha cerrado la boca de los leones, para que no me hiciesen ningún mal» ${ }^{66}$ y todos los movimientos del asna de Balaam son por obra de un ángel» ${ }^{67}$. Parece como si aquí se adelantara Mimónides al ocasionalismo de Malebranch, pero con la mediación angélica. Pero hay más, Maimónides llega a afirmar que «el término mal'âk es polivalente y comprende las Inteligencias, las esferas y los elementos, pues todos ellos ejecutan el mandato soberano» ${ }^{68}$.

Dos prejuicios subyacen en esta doctrina de Maimónides: el primero es considerar que Dios es tan trascendente al mundo que nada hace directamente sobre la realidad — «nunca encontrarás realice Dios (...) acto alguno sino por ministerio de un ángel» ${ }^{69}$-, porque piensan que ello supondría menoscabo en la dignidad divina, o cambio en Dios, lo cual supone imperfección. Dios actúa, según Maimónides, a través de poderes intermedios, a todos los cuales llama «ángeles». «Los Doctores (...) ya-expusieron, para el verdadero sabio, que cada una de las fuerzas corporales es un ángel, cuánto más las que están difundidas por el universo y cada una de ellas posee determinada actividad peculiar y no dos» ${ }^{70}$. Pese a la amplitud de la angeología maimonídea, éste restringe en su tratado La guía de perplejos, la acepción de la palabra: «Aquí hablamos únicamente de los ángeles como inteligencias separadas, dado que nuestra Ley no rechaza el gobierno de este mundo por Dios (jensalzado sea!) mediante los ángeles» ${ }^{71}$.

Como vemos el concepto de ángel es muy amplio. En efecto, nos dice que «todas las energías individuales, tanto físicas como psíquicas, se denominan ángeles (...). Dado que se ha contrapuesto a ese aspecto otro texto, en que se afirma que son estables los ángeles - y, en efecto, reiteradamente se ha expuesto que son vivientes y estables-, la respuesta es que unos son permanentes y otros perecederos. $Y$ tal es la realidad, puesto que las fuerzas individuales nacen y mueren de continuo, en tanto que las especies correspondientes son perdurables, sin deterioro» ${ }^{72}$.

Resulta entrañable la afirmación de Maimónides, que toma de el Midrás Qohèlet, de que «mientras duerme el hombre, su alma conversa con el angel y éste con el querubín, con lo cual dieron a entender a quien comprende y piensa que la facultad imaginativa también se llama angel, y el intelecto querubín, lo cual parecerá perfectamente al hombre instruido, pero desagradará de gran manera a los indoctos» ${ }^{73}$. La imaginación, como vemos en este texto, es el angel de Dios que nos inspira los sueños, siempre en diálogo con la inteligencia, que pone orden y sentido en la capacidad creadora de la imaginación.

Maimónides nos hacer ver un mundo poblado de ángeles, como Tales de Mileto lo concibió lleno de dioses ${ }^{74}$. Vale la pena hacer constar que esa equiparación de los «ángeles» con lo que en la tradición pagana se llamaban «daimones» o dioses menores es hecha por el mismo Maimónides, el cual escribe: «...Dios, como juez (o dominador) que es de los ángeles, razón por la cual se dice: «Porque Yavé, vuestro Dios, —dirigiéndose a todo el linaje humano- es el Dios de los dioses, es decir, de los ángeles ${ }^{75}$. Valga el siguiente texto para comprender hasta qué punto se extiende la concepción angélica de Maimónides: «Pero si le dices que Dios (¡ensalzado sea!) puso en el semen una fuerza germinativa que modela y estructura esos miembros

66. Daniel, 6 .

67. Maimónides: l. c., p. 262.

68. Maimónides: 1. c., pp. 264-265.

69. Maimónides: 1. c., p. 262.

70. Maimónides: 1. c. p. 263.

71. Maimónides: 1. c., p. 262.

72. Maimónides: 1. c., p. 263.

73. Maimónides: 1. c., p. 264.

74. Aristóteles: De anima, A5, 411 a7.

75. Maimónides: 1. c., p. 261. 
y eso es el ángel ${ }^{76}$. Como vestigio de esta cultura angélica permanece en nuestro lenguaje popular la expresión «tener ángel» cuando realizamos nuestras acciones con acierto e ingenio o su contrario, decimos de una persona que es poco agraciada en su actuar que es un «malage» - expresión que nos recuerda la palabra hebrea mal âk (ángel)_ que equivale a decir que está poseido por un «mal ángel» y cuando una acción está mal hecha decimos que está «desangelada»

El segundo prejuicio es considerar que la materia es una realidad estática y que «solamente el ser animado es susceptible de moverse; por consiguiente, se impone la existencia de un alma (en la esfera) y asimismo algo que impulse el movimiento; es una concepción y el deseo de de lo que ha sido concebido (= conocido), como ya expusimos. Pero esto aquí no puede efectuarse sino por obra de un intelecto (...). No puede por menos de intervenir un ser concebido y que sea objeto de apetencia, conforme quedó expuesto» 77 .

En resumen, según piensa Maimónides, «el conjunto de las cosas creadas se divide en tres partes: primera, las Inteligencias separadas, que son los ángeles; segunda, los cuerpos de las esferas celestes; y tercera, la materia prima, a saber, los cuerpos sujetos a cambio constante, situados bajo la esfera celeste» ${ }^{78}$.

\section{ACTIVIDAD DEL ENTENDIMIENTO ACTIVO}

Nos imaginamos el Entendimiento Activo como un centro de actividad continua, porque «lo incorpóreo e inmaterial —como dice Maimónides- no admite en su esencia posibilidad alguna y cuanto tiene se encuentra siempre en acto» ${ }^{79}$. Pero, pese a ello, Maimónides afirma que «el Intelecto activo, que, según Aristóteles y sus seguidores, está separado, y, no obstante, ora actúa, ora no, como indicó Abû Nasr (Al-Farabí) en su tratado Sobre el Intelecto, en estos términos: «Evidentemente, el Intelecto activo no opera siempre, sino que unas veces sí y otras no». Tales son sus palabras, de meridiana certeza» ${ }^{80}$. Lo sorprendente es que Maimónides afirma que, pese a esa diferencia de actuación o no actuación, «no cabe afirmar que el Intelecto Activo esté sujeto a cambio, ni que de agente en potencia haya pasado al acto por haber obrado en tal momento lo que anteriormente no efectuó» ${ }^{81}$.

Quiere Maimónides salvar a las Inteligencias separadas de la mutabilidad del mundo sublunar, mutabilidad que considera imperfección. Para ello recurre a varios argumentos. En primer lugar establece la diferencia entre la acción de las formas materiales y la de las Inteligencias separadas, especialmente del Entendimiento Agente. «Solamente por equivocidad se denomina acción la de las formas materiales y la del ser separado» ${ }^{82}$. No hay univocidad ni analogía, solamente la coincidencia de la palabra, pero con significados diferentes.

Más sutil es la distinción que hace a continuación. Piensa Maimónides que la acción del Entendimiento Agente es continua e igual, estable, como la luz del sol se expande uniformemente sobre los diversos elementos de la tierra, pero la diferencia está en el receptor, no en el emisor, según el principio clásico medieval: «quidquid recipitur ad modum recipientis recipitur».

Maimónides se expresa así: «Tal vez alguien vea un sofisma en mis palabras, alegando que el Intelecto Activo opera necesariamente en un momento determinado y no en otro, no es por

76. Maimónides: 1. c., p. 263.

77. Maimónides: 1. c., p. 269.

78. Maimónides: 1. c., p. 270 . Insiste más adelante en la p. 271.

79. Maimónides: 1. c., p. 290.

80. Ibidem.

81. Ibidem.

82. Ibidem. 
algo inherente a su esencia, sino en virtud de la disposición de las materias; su acción se ejerce de continuo sobre todo lo dispuesto, y, si algo lo impide, proviene de la situación de la materia, no del Intelecto en sí» ${ }^{83}$. En última instancia Maimónides nos dirá que no pretende averiguar por qué «el Intelecto activo, que está separado, obra en un tiempo y en otro no» ${ }^{84}$, al igual que Dios mismo, cuyos designios nos son desconocidos.

En resumen Maimónides concluye: «Nuestra conclusión es, y debe admitirse como cierta, que el Intelecto Activo, no siendo ni cuerpo, ni fuerza en un cuerpo, actúa en un momento dado, pero no con idéntica acción en otro, sea cual fuere la causa; no se deduce de ahí haya pasado de la potencia al acto, ni que haya habido en su esencia una posibilidad, ni tampoco que precise de un agente para dicho tránsito» ${ }^{85}$.

\section{EL CARÁCTER MEDIÁTICO DEL ENTENDIMIENTO ACTIVO}

Para Maimónides la Metafísica es el supremo saber. «Maimónides parecía plantearse una misión: la de guiar a los judíos a la Metafísica. La sabiduría metafísica era para él el atributo primordial del judaismo, pero se había perdido en el exilio. En su opinión esta pérdida era la tragedia del exilio. El renacimiento de una sabiduría superior, decía, sería el anuncio de la era mesiánica; la recuperación de la filosofía era la acción redentora, que él mismo, el primero en el período del exilio, creía estar iniciando» ${ }^{86}$. Y posteriormente ese mismo autor afirma de Maimónides: «Desde muy temprana edad había considerado ya requisito previo para participar en la vida eterna un mínimo de conocimiento filosófico» ${ }^{87}$, en lo que de nuevo se nos muestra la coincidencia con el pensamiento de Escoto Eriúgena.

Dentro de la Metafísica, considera como la cumbre más alta el conocimiento de Dios, que él califica como «saber profético». «Dondequiera que se habla de sabiduría por excelencia, que es el fin último (del hombre), se trata del conocimiento de Dios» ${ }^{88}$. Y en otro lugar escribe: «La verdadera perfección humana consiste en la adqusición de las virtudes intelectuales, en concebir especies inteligibles que puedan proporcionarnos ideas sanas sobre asuntos metafísicos. En esto estriba el fin último del hombre, que confiere al ser humano una auténtica perfección; le pertenece a él sólo, por ella alcanza la inmortalidad y por ella el hombre es realmente hombre» ${ }^{89}$. Con lo que Maimónides viene a concluir con lo que tantos años más tarde María Zambrano termina su obra El hombre y lo divino: "Y mientras su vida siga siendo tal como es, mientras sea sólo hombre, ser alguien obligado a ser libre y a hacer, a hacerse en la esperanza, que por momentos se exaspera, de ser al fin enteramente, ser enteramente, ser del todo, que sería ser simple creatura; simple hijo de Dios» ${ }^{90}$.

Es muy expresiva la forma como Maimónides nos situa los diferentes saberes en torno y como aproximación a la Metafísica: «Has de saber, hijo mío, que mientras sólo te ocupes de las Ciencias Matemáticas y de la Lógica, eres de los que dan vueltas en torno a la morada y buscan la entrada, como alegóricamente aseveran los Doctores (...); una vez comprendidas las materias de la Física, ya has penetrado en la mansión y te paseas por el vestíbulo; finalmente, después de haber terminado las Ciencias Físicas y estudiado la Metafísica, has comparecido

83. Maimónides: 1. c., pp. 290-291.

84. Maimónides: 1. c., p. 291.

85. Ibidem.

86. Abraham Joshua Heschel: 1. c., p. 262.

87. Abraham Joshua Heschel: 1. c., p. 263.

88. Maimónides: 1. c., p. 562.

89. Maimónides: 1. c., pp. 561-562.

90. $\mathrm{M}^{\mathrm{a}}$ Zambrano: El hombre y lo divino, México/Buenos Aires, FCE., 1966, p. 294. 
ante el soberano, en el patio interior y te encontrarás con él en el mismo aposento. Este último grado es el de los auténticos sabios, pero también aquí se dan diferentes categorías de perfección. Aquellos que, tras de haber dominado la Metafísica, ocupan su pensamineto solamente en Dios, totalmente entregados a Él, alejándose de todo lo que no sea Él, y centran su atención intelectual en reflexionar sobre los seres, con la mira de extraer de ellos la demostración de la existencia de Dios y averiguar cómo Él puede gobernarnos, ésos se encuentran en el salón o sede del sobrerano, es el grado de los profetas» ${ }^{91}$. Este saber es condición del culto verdadero de la Divinidad, aquel que no es puro formalismo religioso, sino conexión racional y entrañable con el Ser supremo. Maimónides escribe: «No hay que entregarse a esa especie de culto sino después de haber concebido (la idea de Dios) por medio del Intelecto; solamente después de haber comprendido a Dios y sus obras en la medida que lo requiere la Inteligencia, podrás consagrarte enteramente a Él y afianzar el vínculo existente entre tú y Él, a saber, el Intelecto» ${ }^{92}$. Con lo que vemos que el Intelecto Activo tiene una función mediática que nos vincula con la Divinidad. Como el mismo Maimónides dice, el Intelecto Activo «es el vínculo existente entre tú y él» ${ }^{93}$.

El intelecto pasivo no es solamente una razón discursiva, sino sobre todo una razón intuitiva, que consiste en la presencia del Intelecto activo en nuestro propio intelecto, el cual sólo actúa iluminado y movido por el Intelecto activo.

«Ya hemos expuesto que ese Intelecto que se derrama sobre nosotros de (parte de) Dios es el vínculo existente entre nosotros y Él» ${ }^{94}$. En otro lugar llama a este derramarse del Intelecto Activo sobre nuestro intelecto «efusión divina que reciben todos cuantos se esfuerzan por conseguirla» ${ }^{95}$. Abraham Joshua Heschel escribe al respecto: «Un poder más alto, el «Intelecto activo», efectúa la materialización de la razón humana y lleva al pensamiento humano de la mera capacidad de pensar a la realidad» ${ }^{96}$. Ahora bien, ese raudal de conocimiento que nos viene de Dios, puede el hombre fomentarlo o impedirlo, hasta terminar negándolo. «De ti deperide tanto el fortalecer y consolidar ese vínculo como debilitarlo y aflojarlo poco a poco, hasta deshacerlo» ${ }^{97}$. ¿Cómo se fortalece ese lazo y vinculación con la Divinidad, una vez despejada la vía del conocimiento? Maimónides lo tiene claro: solamente gracias al amor. «Está claro que, una vez conseguido el conocimiento de Dios, se impone la consagración a Él, ocupando de continuo el pensamiento y la inteligencia en el amor que Le es debido» ${ }^{98}$. Es cierto que esto «generalmente no se consigue sino mediante la soledad y el aislamiento» ${ }^{99}$, con lo que Maimónides busca, como todos los místicos, ese encuentro amoroso, donde se da la plenitud de la vivencia de Dios, el éxtasis, como anteriormente había defendido Plotino. Pueblo santo, comunidad selecta de solitarios que veíamos en la doctrina de otro místico, en este caso el musulmán Al-Farabí.

Las pasiones en la juventud, y los negocios en la madurez, nos distraen de esa meta suprema, de ese «amor Dei intelectualis» de que hablará años más tarde Espinoza. Maimónides se expresa así: «Los filósofos han declarado que en la juventud la pujanza corporal es un obstáculo para la mayoría de las cualidades morales, y con mayor motivo, para ese pensamiento puro resultante de la perfección de las ideas que llevan al hombre a apasionarse de Dios. Es imposible que tal pensamiento surja en tanto dure la ebullición de los humores corporales; pero

91. Maimónides: 1. c., p. 549.

92. Ibidem.

93. Ibidem.

94. Maimónides: I. c., p. 550.

95. Maimónides: 1. c., p. 553.

96. Abraham Joshua Heschel: 1. c., p. 184.

97. Maimónides: 1. c., p. 550.

98. Ibidem.

99. Ibidem. 
a medida que las fuerzas del cuerpo van remitiendo y el ardor de los deseos se extingúe, la inteligencia se acabala, su luz aumenta, su comprensión gana en lucidez y experimenta un goce más intenso por lo que ha comprendido, de manera que en el hombre agobiado por la pesadumbre de los años y próximo a la muerte, dicha comprensión adquiere un mayor asentamiento, confiere un placer más acendrado e inspira una verdadera pasión hacia su objeto, hasta que, finalmente, en plenitud de éste el alma se separa del cuerpo» ${ }^{100 .}$

En tiempos en que Maimónides pasó por Ceuta (1165) vivía en aquella ciudad un sabio y joven judío llamado Yosé Ben Yehudá ibn Aknin, que escribió un tratado comentando el Cantar de los Cantares e interpretándolo como la relación del hombre con el Intelecto Activo. El amado era una metáfora de Intelecto Activo y la amada una metáfora del alma racional.

\section{LA MISIÓN PROFÉTICA DEL-ENTENDIMIENTO ACTIVO}

El carácter mediático del Entendimiento agente, se realiza en su expresión superior como profecía. «Sábete que, en realidad de verdad, la profecía es una emanación de Dios (...) mediante el Intelecto activo sobre la facultad racional en primer término, y seguidamente sobre la imaginativa y constituye el más alto grado del hombre y el ápice de la percepción asequible a su especie, y tal estado es la culminación de la facultad imaginativa, al alcance de cualquier hombre, ni es accesible por el mero perfeccionamiento en las ciencias especulativas ni el mejoramiento en la conducta, por muy perfectas y bellas que puedan ser, sin que se junte la máxima perfección posible de la facultad imaginativa en su primitiva formación» ${ }^{101}$.

Es interesante observar la importancia que Maimónides concede a la imaginación, frente a la postura racionalista que la ningunéa o rechaza como desviación fantasiosa del discurso racional. Maimónides nos describe las funciones y «operaciones» de dicha facultad imaginativa que, según él, son: «conservar el recuerdo de las cosas sensibles y combinarlas, así como lo específico de su naturaleza es reproducir y su más alta y noble actividad se realiza cuando los sentidos cesan en sus funciones: entonces es cuando sobreviene una especie de inspiración, conforme a su disposición, que es la causa de los sueños verdaderos y de la profecía, en que no hay diferencia específica, sino solamente en más o en menos» ${ }^{102}$. Esa reducción de la profecía al sueño es reminiscencia de una vieja idea en nuestra cultura, la extrañeza ante la presencia de los sueños que, al no estar sujetos a nuestra voluntad, se pensaban como infundidos por una realidad extraña a nosotros mismos, como si la Divinidad nos poseyera en ese momento en que el sueño nos aisla de la posesión de nosotros mismos.

Pero, por otra parte, el significado peyorativo de la palabra «sueño», que está también presente en nuestra tradición cultural como nadería, humo vacío de una imaginación exaltada, parece devaluar el hecho de la profecía al asimilarla al sueño. Mas para Maimónides la profecía constituye el supremo valor del ser humano y el momento en que la identificación con la Divinidad se da en su más alta expresión posible.

No debe entenderse aquí tampoco el sueño como se interpreta en nuestra cultura barroca, que le hace decir a Calderón que «toda la vida es sueño, y los sueños sueños son», texto que inspiró la obra del empirista Berkeley, en el sentido de que toda la realidad se reduce a sueño, de forma que somos, según afirma Quevedo, sueños de Dios.

Esa relación entre el sueño y la profecía fue objeto de estudio en la larga tradición cabalística. Nos sorprende la afirmación de Maimónides: «Ya sabes que los doctores aseveraron reiteradas veces: «el sueño es una sesentava parte de la profecía. Sin embargo, no cabe entre dos

100. Maimónides: 1. c., p. 555.

101. Maimónides: 1. c., p. 344.

102. Maimónides: 1. c., p. 345. 
cosas específicamente distintas, ni sería acetado decir, p. e., que la perfección del hombre es tantas o cuantas veces la del caballo» 103 .

Parece contradecir este texto al que al comienzo de este apartado he citado, pero en realidad no hay contradicción. Para Maimónides la profecía y el sueño son «dos cosas específicamente distintas», pero procedentes ambas de la imaginación, que es una de las funciones del Entendimiento Agente. Más aún, la profecía puede darse, según nos dice Maimónides, en sueño o en visión ${ }^{104}$. En otro lugar afirma: «En estas dos partes, a saber, visión y sueño se encierran todos los grados de profecía» ${ }^{105}$. Pero eso no quita que Maimónides pueda afirmar que «la acción de la potencia imaginativa durante el sueño es idéntica a la de la profecía, salvo su insuficiencia y que no alcanzó su perfección» ${ }^{106}$. Entre los Rabinos circulaba la afirmación: «el sueño es fruto abortivo de la profecía», a lo que Maimónides añade el siguiente comentario: «Sorprendente comparación, dado que éste (el sueño) no es sino el mismo fruto, pero malogrado de su perfecta madurez» ${ }^{107}$.

Lo que quiere darnos a entender Maimónides es que la profecía no pertenece al campo de la episteme, sino de la nous, esto es, se trata de una intuición, visión, según dice Maimónides. Y aclara: «El término «visión» (mar â) se deriva de «ver», porque ocurre a la facultad imaginativa que obra con tal verismo, que percibe el objeto como si existiera exteriormente, y que es igual que si se presentara por vía de sensación externa» ${ }^{108}$. Los objetos percibidos en el sueño son los mismos que los de la sensación externa, que queda suplida en el caso del sueño por la función imaginativa del Entendimiento Agente, que «se derrama sobre ella» ${ }^{109}$. «Por consiguiente - dice más adelante-, si un individuo, tal como queda descrito, con la imaginativa en grado sumo y en plena actividad, y derramándose sobre ella el Intelecto Activo, conforme a la perfección especulativa de tal sujeto, se diera el caso de percibir cosas divinas, maravillosas, no vería más que a Dios y a sus ángeles, y la ciencia que le sería asequible sólamente se polarizaría en opiniones verdaderas y normas de conducta ordenadas a las relaciones mútuas entre los humanos» ${ }^{110}$.

Posteriormente nos dirá Maimónides que en razón de tres cosas superan unos hombres a otros: en razón de la «perfección en la facultad racional mediante el estudio de la facultad imaginativa en su primitiva formación, y de la ética derivada del comportamiento intelectual» ${ }^{111}$. En donde volvemos a ver la distinción entre la «razón discursiva» y la «intuitiva», a la que asigna la imaginación capacidad creadora o poética, en expresión de la filósofa María Zambrano.

«Cúmpleme llamar tu atención — dice Maimónides- sobre la naturaleza esencial de esta emanación divina proyectada sobre nosotros, mediante la cual pensamos y que marca la superioridad individual de nuestras inteligencias» ${ }^{112}$. La emanación del Entendimiento Agente sobre el entendimiento individual se realiza en diversos niveles. «Has de saber que si tal emanación del Intelecto activo se derrama únicamente sobre la facultad racional, con exclusión de la imaginativa, bien por insuficiencia de la emanación, bien por defecto de la imaginativa en su formación primitiva, que la imcapacita para su recepción, es la clase de los sabios especulativos. Por el contrario, si tal emanación se difunde conjuntamente sobre ambas facultades, a

103. Ibidem.

104. Ibidem.

105. Ibidem.

106. Ibidem.

107. Ibidem.

108. Ibidem.

109. Ibidem.

110. Maimónides: 1. c., p. 346.

111. Maimónides: 1. c., p. 347.

112. Maimónides: 1. c., p. 348. 
saber: la racional y la imaginativa, como ya expusimos, al igual que algunos filósofos, y ésta ha sido creada primitivamente en toda su perfección, entonces será la clase de los profetas. En fín, si la emanación recae exclusivamente sobre la facultad imaginativa, sin intervención de la racional, sea por razón de su formación primitiva, o bien por falta de ejercicio, tendremos la clase de los estadistas, legisladores, adivinos, agoreros y forjadores de sueños verdaderos» ${ }^{113}$. En esta tercera clase incluye también Maimónides los milagreros, no sabios, etc. Estos pueden alcanzar incluso «maravillosas visiones», pero su artificio no va acompañado de una racionalización de sus experiencias. «Todo esto - afirma - es debido al predominio de la facultad imaginativa, con mengua de la racional» ${ }^{114}$.

Maimónides nos hace ver que ambas facultades: la puramente racional y la imaginativa, se dan en todo hombre en mayor o menor grado, o, como él dice, «se dan numerosas gradaciones» ${ }^{115}$, pero esas facultades se ponen en acto gracias a que el Intelecto Activo se «derrama», como hemos visto, sobre ellas, pero la eficacia de éste está condicionada por la gradación o desarrollo de tales facultades. El abuso de la sola imaginación da lugar a desvaríos, pero, por el contrario, la falta o escasa efusión de ésta, nos da intelectuales chatos, miopes, que no alcanzan a ver los problemas más profundos de la Filosofía ${ }^{116}$. «Por eso — concluye- no ha de otorgarse crédito a quienes no tengan una facultad raciocinativa perfecta ni han alcanzado un alto nivel especulativo, pues solamente quien lo logró es capaz de conseguir ulteriores conocimientos cuando el Intelecto divino se infunde sobre él, es el profeta auténtico» ${ }^{117}$.

Como dice Abraham Joshua Heschel, Maimónides «parece que se preparó con la mayor dedicación para recibir la inspiración profética. Estaba convencido de que las cualidades personales eran el fundamento sobre el que se podía construir el hombre profético, que «nadie recibe el don de la profecía hasta que todas las virtudes intelectuales y la mayoría de las morales, el valor y la moderación, forman parte de él» ${ }^{118}$.

Maimónides parte de los esquemas típicamente medievales, de que la razón está al servicio de la fe, en la que tiene su último fundamento y protección. «Maimónides buscaba la profecía porque, a partir de su juventud, había tomado conciencia de las limitaciones de la inteligencia» ${ }^{119}$. Pero, sobre todo, la simple razón no aporta el sentido de la existencia. «Este afán de entender el sentido de la existencia individual y el convencimiento de que el pensamiento filosófico era incapaz de aclarar esta cuestión fueron factores que fomentaron aún más su interés por la profecía» ${ }^{120}$. Y posteriormente continúa: «Tanto en sus primeras especulaciones filosóficas como en su contemplación madura, el problema del sentido y el fin de cada existencia individual definieron las fronteras de lo que podía tener una solución filosófica. «La capacidad del entendimiento humano no basta para conocer el fin de todas y cada una de las cosas, sólo la gracia puede descifrar hasta las cuestiones más obvias. La imaginación, que no identifica más que lo particular, el objeto individual concreto, es, junto con la inteligencia, el órgano del conocimiento profético» ${ }^{121}$.

\footnotetext{
113. Ibidem.

114. Ibidem.

115. Ibidem

116. Maimónides: 1. c., pp. 350-351.

117. Maimónides: 1. c., p. 351.

118. Abraham Joshua Heschel: 1. c., p. 40.

119. Ibidem

120. Ibidem

121. Abraham Joshua Heschel: l. c., p. 41.
} 


\title{
7. EL CARÁCTER REAL DEL ENTENDIMIENTO ACTIVO
}

Una cosa queda clara en la doctrina de Maimónides sobre el Entendimiento Agente, el rango que le atribuye en la vida humana: «Quien desee alcanzar la perfección humana y ser con toda verdad hombre de Dios, se penetrará bien de esta idea: que el rey excelso que le acompaña y se une a él constantemente excede en magnitud a cualquier persona humana (que fuera rey), aunque fuese David o Salomón. Ese rey que así se le une y le acompaña es el Intelecto que sobre nosotros se derrama y es el vínculo entre nosotros y Dios; y lo mismo que nosotros Le percibimos por medio de esa luz, que Él derrama, según lo dicho: «En tu luz vemos la luz» ${ }^{122}$, de igual manera por mediación de esa luz Él nos observa y está siempre con nosotros, envolviéndonos en su mirada: «por mucho que uno se oculte en escondrijos, ¿no lo veré Yo?» 123 .

Con lo cual vemos la dignidad que atribuye Maimónides al Entendimiento Agente, «que excede en magnitud a cualquier persona humana», él es el rey que se derrama sobre nosotros como una luz interior, gracias a la cual también Dios nos observa, con lo que el carácter medial del Entendimiento Agente se convierte en vía de comunicación entre Dios y el hombre. Pero como queda patente por las imágenes aportadas, ese conocimiento que adquirimos y se «derrama» sobre nosotros del Entendimiento Agente es un tipo de intuición, porque «intuir» es «ver» y sólo es posible ver con la luz. El Entendimiento Agente actúa así como una especial manera de iluminación, de donación de ciertas verdades y principios intelectuales que nos posibilitan el acceder a la que él llama «ciencia pura» de la que nos dice que «ésta es la que ofrece demostración» ${ }^{124}$. Y más adelante insiste: «esa ciencia que nos brinda la demostración para las ideas (filosóficas) contenidas en la Ley» ${ }^{125}$. Dos aclaraciones conviene hacer aquí: en primer lugar que a Maimónides en tanto le interesa la Filosofía en cuanto es usada como instrumento para la fe, y en segundo lugar, que la palabra «Ley» se usa aquí como sinónimo de todo el legado del mensaje revelado.

Pero sobre ella y previo a ella, tenemos las intuiciones intelectuales o verdades de razón de las que nos dice Maimónides: «Ahora bien, dado que las verdades de orden intelectual son admitidas tradicionalmente sin demostración por métodos especulativos en los Libros de los Profetas y en los dichos de los Doctores» ${ }^{126}$.

\author{
Juan Fernando Ortega Muñoz \\ Departamento de Filosofía \\ Campus de Teatinos \\ Universidad de Málaga \\ 29071 Málaga
}

122. Salmo 36 .

123. Jeremías 23; Maimónides: l. c., p. 556.

124. Maimónides: 1. c., p. 560.

125. Ibidem.

126. Ibidem. 